CLINICAL STUDY

\title{
Postoperative mortality in parathyroid surgery in Sweden during five decades: improved outcome despite older patients
}

\author{
S Norenstedt ${ }^{1}$, A Ekbom $^{2}$, L Brandt $^{2}$, J Zedenius ${ }^{1}$ and I-L Nilsson ${ }^{1}$ \\ ${ }^{1}$ Endocrine Surgery Unit, Department of Molecular Medicine and Surgery and ${ }^{2}$ Clinical Epidemiology Unit, Department of Medicine, Karolinska Institutet, \\ Karolinska University Hospital, SE 17176 Stockholm, Sweden
}

(Correspondence should be addressed to S Norenstedt; Email: sophie.norenstedt@capio.se)

\begin{abstract}
Objective: Primary hyperparathyroidism (pHPT) is a common endocrine disorder. In Europe, pHPT has been associated with premature death in cardiovascular disorders. Our question was whether the risk of postoperative death has been affected by the increased proportion of elderly patients referred for parathyroid surgery.

Methods: The nationwide Cancer Registry and Causes-of-Death Registry were used to analyze mortality among 14635 Swedish patients subjected to parathyroid adenomectomy (PTx) during 1961-2004. Standard mortality ratios (SMR) and the 95\% confidence intervals (CI) were calculated with the entire Swedish population as control, standardized for age, gender and calendar year.

Results: The observation period was more than 166000 person-years. The overall perioperative (30day) mortality rate was $1.3 \%$ (185/14 635; SMR 7.9; CI 6.82-9.15); 1.1\% for women (132/11 500; SMR 7.56; CI 6.32-8.96), and 1.7\% for men (53/3135; SMR 9.01; CI 6.75-11.78). Cardiovascular disorder was the dominant cause of death in both sexes and in all the investigated age groups (age 1554 years; SMR 29.0; CI 9.42-67.71, age 55-74 years; SMR 6.12; CI 3.96-9.03, age 75 years: SMR 5.26; CI 3.74-7.19). The SMR decreased over the calendar year period notwithstanding a rising proportion of elderly individuals. In the most recent period, 1997-2004, the perioperative mortality rate was only $0.5 \%$, which represents a normalization of the excess mortality risk during the first postPTx year (SMR 1.17; CI 0.92-1.46).

Conclusion: PTx is a safe procedure, regardless of patient age. Today, the perioperative mortality risk is not a reason for excluding elderly patients from parathyroid surgery.
\end{abstract}

European Journal of Endocrinology 160 295-299

\section{Introduction}

Primary hyperparathyroidism (pHPT) is a common endocrine disorder, often detected by routine measurement of serum calcium levels. The clinical profile has shifted from a disease with pronounced renal, skeletal, and mental symptoms to a more diffuse symptomatology. Today, pHPT appears to be associated with an overrepresentation of cardiovascular dysfunction, diabetes mellitus, and dyslipidemia (1). PHPT, at least in Europe, has been associated with premature death, especially in cardiovascular disorders (2-4). The risk of dying applies to both sexes and all age groups and normalizes with time after parathyroid adenomectomy (PTx), while hypercalcemia treated conservatively still carries a slightly elevated risk of premature death $(4,5)$.

The only definite treatment of pHPT is parathyroid surgery. Today, better techniques for the preoperative localization of a parathyroid adenoma with ultrasonography and/or parathyroid scintigraphy permit a less invasive surgical approach. Since life expectancy has risen and the threshold for referral of pHPT patients for
PTx has been lowered, the proportion of elderly patients has increased. Data on morbidity and mortality after PTx in elderly people are conflicting. Some authors report quite high-risk estimates, others claim a benefit of PTx for all age groups (6-10). The aim of this study was to analyze all cause mortality within 30 days and 1 year after PTx.

\section{Materials and methods}

A cohort of 14635 Swedish patients (11 500 women) subjected to PTx during the period from January 1961 to December 2004 was generated from the Swedish National Cancer Registry (Table 1). Requisites for patient inclusion were histological verification of the adenoma at routine microscopic examination by a qualified pathologist and clinical features supporting the diagnosis of parathyroid adenoma. Since 1958, all malignant and a few benign tumors, including parathyroid adenomas, have to be reported to the Cancer Registry, both by the treating physician and by 


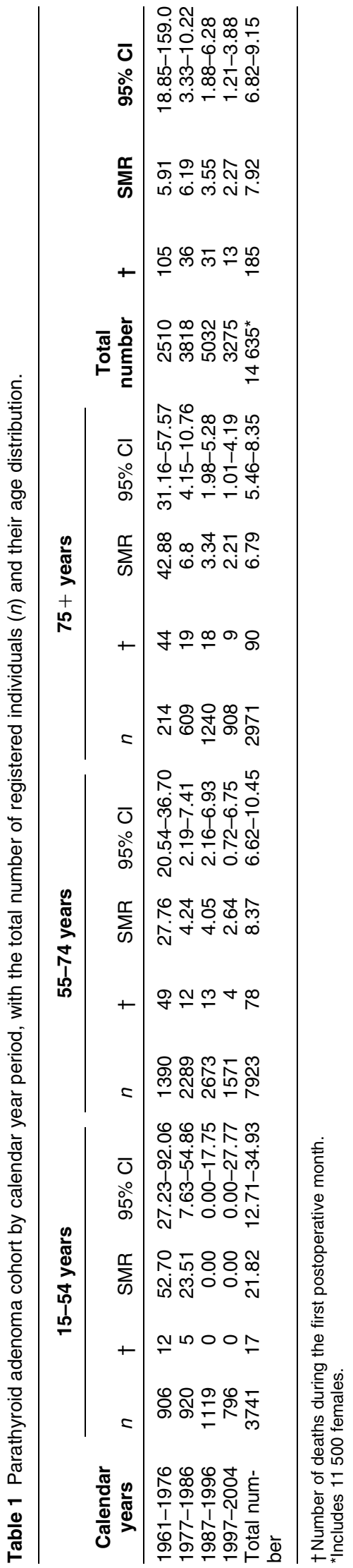

the pathologist who establishes the diagnosis. Only patients with a single adenoma were included, not those with parathyroid hyperplasia. The information in the Cancer Registry includes date of diagnosis, type of tumor and diagnosis coded according to the International Classification of Diseases (ICD), version 7. The Cancer Registry has been validated and underreporting is $2-3 \%(11)$.

Mortality in the cohort was derived from the National Causes-of-Death Registry from 1961 until the end of 2004. This register includes all deaths from 1952 onwards among registered Swedish residents. It also contains the underlying and contributory causes of death from the physician's death certificate in accordance with ICD-7, 8, and 9, and the date of death. The accuracy of the data concerning disease groups has been considered reliable (12).

Matching between registers was achieved by means of the individual National Registration Number that is allocated to every Swedish resident. The person-year at risk was counted from the date of entry into the cohort until death, emigration or the end of the observation period, i.e., 31 December, 2004. Standard mortality ratios (SMR) were calculated with the entire Swedish population as control, standardized for age, gender, and calendar year. SMR are calculated as the ratio of the observed to the expected number of deaths and used as an indicator of risk. Nationwide statistics from the Causes-of-Death Registry include annual sex- and agespecific mortality rates for different ICD codes. The expected number of deaths in the observed population was calculated by multiplying the number of personyears at risk for each 5-year age group, gender, and calendar year, by the corresponding age, gender, and calendar year-specific mortality rates in the general population. The $95 \%$ confidence interval (CI) of SMR was calculated on the assumption that the number of deaths in various categories follows the Poisson distribution. Various stratification studies have been conducted, which include age and calendar year at entry, the duration of follow-up, attained age, gender, and various combinations.

\section{Results}

Of the $14635 \mathrm{pHPT}$ patients in the cohort, $79 \%$ were women. The observation time was more than 166000 person-years. The mean age of the patients increased from 53 years during 1961-1971 to 64 years during 1992-2004 $(p<0.0001)$. Nearly, 3000 of the pHPT patients were 75 years of age or more at the time of PTx and this age group constituted more than a quarter of the cases in the most recent period (1997-2004). During the entire period, 185 patients died within 1 month and 365 during the next 11 months after PTx (Table 2). The overall 30-day mortality after PTx was $1.3 \%$ (185/14 635; SMR 7.92; CI 6.82-9.15); $1.1 \%$ for women (132/11 500; SMR 7.56; CI 6.32-8.96), and 
Table 2 Standard mortality ratio with 95\% confidence interval and the number of deaths after parathyroid adenomectomy by calendar year periods.

\begin{tabular}{|c|c|c|c|c|c|c|}
\hline \multirow[b]{2}{*}{ Calendar year } & \multicolumn{3}{|c|}{ First month after Ptx } & \multicolumn{3}{|c|}{ 2-12 months after Ptx } \\
\hline & $n$ & SMR & $95 \% \mathrm{Cl}$ & $n$ & SMR & $95 \% \mathrm{Cl}$ \\
\hline $1961-1976$ & 105 & 34.78 & $28.45-42.11$ & 66 & 2.05 & $1.58-2.60$ \\
\hline $1977-1986$ & 36 & 6.21 & $4.35-8.59$ & 116 & 1.77 & $1.46-2.12$ \\
\hline 1987-1996 & 31 & 3.52 & $2.39-5.00$ & 118 & 1.17 & $0.97-1.40$ \\
\hline $1997-2004$ & 13 & 2.27 & $1.21-3.88$ & 65 & 1.07 & $0.82-1.36$ \\
\hline Total number & 185 & 7.92 & $6.82-9.15$ & 365 & 1.40 & $1.26-1.56$ \\
\hline
\end{tabular}

$n$, number of deaths; SMR, standardized mortality ratio; CI 95, 95\% confidence interval.

1.7\% for men (53/3135; SMR 9.01; CI 6.75-11.78). An analysis of the 30-day mortality over time showed a decrease from $4.2 \%$ during $1961-1976$ to $0.4 \%$ during 1997-2004. The mortality during day 31 to day 365 after PTx ceased to be significantly increased from 1987 onwards.

The causes of death within the first month and the following 11 months after PTx are listed in Table 3. The dominant causes of mortality during the first month after PTx were cardiovascular (37\%), endocrine (32\%), and malignancy-related $(17 \%)$, demonstrable in both genders and in all the investigated age groups (Tables 4 and 5). Of the patients who died within the first year after PTx, 51\% did so from a cardiovascular disorder. The second and third causes in absolute terms were tumors and endocrine disorders (around 15\% each). The number of deaths in endocrine disorders decreased from 41 in 1961-1976 to four during the latest time period. (Table 5).

\section{Discussion}

The key finding in the study was a decrease in the postoperative mortality risk during the observation period notwithstanding the increasing mean age of individuals subjected to PTx.

The cohort was recruited from the nationwide Swedish Cancer Registry, to which parathyroid adenomas together with all hormone-producing tumors are compulsory reported by the treating physician as well as by the examining pathologist. The material and the study design have some limitations. The cohort represents persons with diagnosed pHPT who underwent PTx in accordance with the prevailing routine. Since many cases are not diagnosed or are not referred for PTx, the cohort cannot be said to represent the entire Swedish pHPT population. Also, the Swedish Cancer Registry from which patients were recruited does not contain any information about parathyroid hyperplasia, which is not reported to the Registry. Consequently, the study does not include some $15 \%$ of persons with pHPT. The main limitation of the study is that the registers contain no detail about the degree of hypercalcemia, symptoms, surgical procedure, and postoperative serum calcium levels.

However, the size of the investigated cohort, 14635 patients subjected to PTx, provides sufficient statistical power for the analysis of postoperative mortality. The registry is well validated. Missing reports of other

Table 3 Standard mortality ratio with 95\% confidence interval and the number of deaths during the first month and the following 11 months after parathyroid adenomectomy.

Mortality after parathyroid adenoma surgery 1961-2004

\begin{tabular}{|c|c|c|c|c|c|c|}
\hline \multirow{3}{*}{$\begin{array}{l}\text { Disease group } \\
\text { (ICD) }\end{array}$} & \multicolumn{6}{|c|}{ Mortality after parathyroid adenoma surgery 1961-2004 } \\
\hline & \multicolumn{3}{|c|}{ First month after PTx } & \multicolumn{3}{|c|}{ 2-12 months after PTx } \\
\hline & $n$ & SMR & $95 \% \mathrm{Cl}$ & $n$ & SMR & $95 \% \mathrm{Cl}$ \\
\hline Cardiovascular & 69 & 5.91 & $4.60-7.58$ & 213 & 1.63 & $1.42-1.87$ \\
\hline Endocrine & 59 & 119.20 & $90.73-153.7$ & 18 & 3.25 & $1.92-5.13$ \\
\hline Tumor & 31 & 5.02 & $3.41-7.12$ & 53 & 0.78 & $0.58-1.02$ \\
\hline Respiratory & 9 & 6.11 & $2.80-11.61$ & 18 & 1.08 & $0.64-1.71$ \\
\hline Urogenital & 5 & 16.03 & $5.20-37.40$ & 28 & 8.06 & $5.35-11.65$ \\
\hline Gastrointestinal & 5 & 6.54 & $2.12-15.27$ & 9 & 1.06 & $0.49-2.02$ \\
\hline Trauma/violence & 4 & 4.73 & $1.29-12.11$ & 12 & 1.30 & $0.67-2.26$ \\
\hline Infectious & 1 & 4.67 & $0.12-26.04$ & 7 & 2.97 & $1.20-6.12$ \\
\hline Autoimmune & 1 & 7.58 & $0.19-42.21$ & 0 & 0.00 & $0.00-2.49$ \\
\hline Neurological & 1 & 2.77 & $0.07-15.43$ & 2 & 0.50 & $0.06-1.79$ \\
\hline Hematological & 0 & 0.00 & $0.00-63.25$ & 0 & 0.00 & $0.00-5.67$ \\
\hline Psychiatric & 0 & 0.00 & $0.00-7.21$ & 3 & 0.51 & $0.10-1.48$ \\
\hline Total number & 185 & 7.92 & $6.82-9.15$ & 365 & 1.40 & $1.26-1.56$ \\
\hline
\end{tabular}

ICD, International Classification of Diseases; SMR, standardized mortality ratio; CI 95, 95\% confidence interval; $n$, number of deaths. 


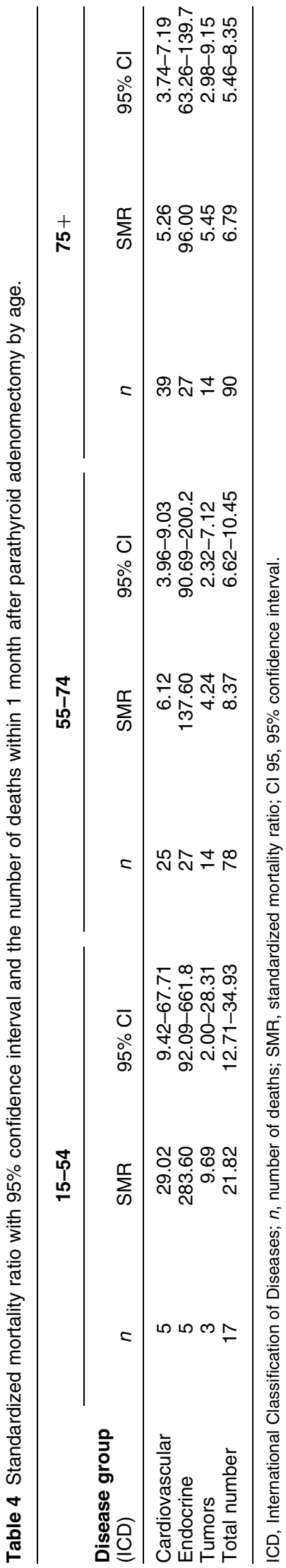

Table 5 The main causes of death during different time periods.

\begin{tabular}{lcccc}
\hline $\begin{array}{l}\text { Disease } \\
\text { group (ICD) }\end{array}$ & $\begin{array}{c}\text { 1961-1976 } \\
\text { (n) }\end{array}$ & $\begin{array}{c}\text { 1977-1986 } \\
\text { (n) }\end{array}$ & $\begin{array}{c}\text { 1987-1996 } \\
\text { (n) }\end{array}$ & $\begin{array}{c}\text { 1997-2004 } \\
\text { (n) }\end{array}$ \\
\hline Cardiovascular & 33 & 16 & 15 & 7 \\
Tumor & 17 & 2 & 11 & 1 \\
Respiratory & 6 & 3 & 0 & 1 \\
Endocrine & 41 & 9 & 5 & 4 \\
\hline
\end{tabular}

ICD, International Classification of Diseases; $n$, number of deaths.

tumors is less than 3\% (11). The validity of physicians' certificates on causes of death is satisfactory when diagnoses are grouped according to the major ICD classes (12). Long-term follow-up studies indicate that more than $95 \%$ of the patients had reversed hypercalcemia after the operation $(13,14)$.

The mortality ratio relative to the general background population may not be applicable to the early postoperative period (15). The risk of death after surgery is a combination of the risk of death due to the illness per se and the risk associated with the operation. The perioperative mortality rate is higher than for other elective surgical procedures such as inguinal hernial repair, thyroidectomy or cataract operations (15-17). However, the pHPT group probably includes cases with non-cured malignant hypercalcemia and in some instances the indication for surgery can be classified as semielective. Mild hypercalcemia discovered in population-based screening has also been associated with excess cardiovascular mortality, albeit during a 25-year follow-up (5). In addition, the higher the calcium or parathyroid hormone levels, the higher the mortality risk (18). Analysis of more than 15000 Swedish pHPT patients with a single adenoma or multiglandular parathyroid disorder showed an increased mortality risk beyond the first postoperative year after PTx $(4,19)$. The first postoperative year was omitted from these analyses to exclude mortality related to the operative procedure as such. The risk, which applied to both sexes and all age groups, persisted over 15 years after parathyroidectomy.

The percentage of patients who died within the first month after PTx decreased from $4.2 \%$ in the earliest period to $0.4 \%$ in the most recent period, and from 1987 onwards there was no excess mortality risk from day 31 to 365 after PTx. There are several factors that may contribute to this development. Serum calcium has become a routine test, leading to an earlier diagnosis and less severe disease at the time of surgery. Modern anesthetic procedures and better postoperative care may also affect postoperative mortality. Improved medical treatment of a number of chronic diseases makes it possible to accept patients with a certain degree of comorbidity for surgery.

As could be expected from earlier reports, the dominant cause of death during the first month and first year after PTx was cardiovascular disease and the 
risk estimates were similar for both genders and all ages. Several risk factors for the development of cardiovascular disorders are overrepresented in patients with pHPT (20). It may be assumed that the duration of disease is an important prognostic factor since the risk of dying is related to the degree of hypercalcemia and the weight of the parathyroid adenomas (18). Confounding by indication is a problem in studies of this kind and could explain the increased mortality rate related to tumor diagnoses, especially as pHPT is associated with an increased prevalence of some malignancies (21).

The aim of the present study was to analyze all cause mortality within 1 month and the following 11 months after PTx. Although PTx is usually regarded as a safe procedure, hypercalcemic crisis still carries a significant mortality, especially in patients with extremely highserum calcium levels $(22,23)$. Furthermore, conventional PTx under general anesthesia for high-risk pHPT has been associated, especially in elderly patients, with mortality, and morbidity rates as high as $9 \%$. In our country, more than $99 \%$ of PTx are performed under general anesthesia (24). The present study includes a total of almost 3000 pHPT patients who were over 75 years of age at the time of the operation. Although a selection bias may exist, we conclude that chronological age per se is no reason for abstaining from surgical treatment of pHPT. When deciding treatment of pHPT, the patient's age should therefore be less important than other criteria.

\section{Declaration of interest}

The authors declare that there is no conflict of interest that could be perceived as prejudicing the impartiality of the research reported.

\section{Funding}

This study was supported by grants from the Swedish Cancer Society, the Karolinska Institute and the Swedish Society of Medicine.

\section{References}

1 Lundgren E, Rastad J, Thrufjell E, Akerström G \& Ljunghall S. Population-based screening for primary hyperparathyroidism with serum calcium and parathyroid hormone values in menopausal women. Surgery 1997121 287-294.

2 Ronni-Sivula H. Causes of death in patients previously operated on for primary hyperparathyroidism. Annales Chirurgiae et Gynaecologiae $1985 \mathbf{7 4} 13-18$.

3 Walgenbach S, Hommel G \& Junginger T. Outcome after surgery for primary hyperparathyroidism: 10-year prospective follow-up study. World Journal of Surgery $2000 \mathbf{2 4} 564-570$.

4 Nilsson IL, Yin L, Lundgren E, Rastad J \& Ekbom A. Clinical presentation of primary hyperparathyroidism in Europe - nationwide cohort analysis on mortality from nonmalignant causes. Journal of Bone and Mineral Research 200217 68-74.

5 Lundgren E, Lind L, Palmer M, Jakobsson S, Ljunghall S \& Rastad J. Increased cardiovascular mortality and normalised serum calcium in patients with mild hypercalcemia followed for 25 years. Surgery $2001130978-985$.
6 Chigot JP, Menegaux F \& Achrafi H. Should primary hyperparathyroidism be treated surgically in elderly patients older than 75 years? Surgery 1995117 397-401.

7 Ohrvall U, Akerstrom G, Ljunghall S, Lundgren E, Juhlin C \& Rastad J. Surgery for sporadic primary hyperparathyroidism in the elderly. World Journal of Surgery 199418 612-618.

8 Conroy S, Moulias S \& Wassif WS. Primary hyperparathyroidism in the older person. Age and Ageing 200332 571-578.

9 Egan KR, Adler JT, Olson JE \& Chen H. Parathyroidectomy for primary hyperparathyroidism in octogenarians and nonagenarians. A risk-benefit analysis. Journal of Surgical Research 2007140 194-198.

10 Kebebew E, Duh QY \& Clark OH. Parathyroidectomy for primary hyperparathyroidism in octogenarians and nonagenarians: a plea for early surgical referral. Archives of Surgery 2003138 867-871.

11 Mattsson B \& Wallgren A. Completeness of the Swedish Cancer Register. Non-notified cancer cases recorded on death certificates in 1978. Acta Radiologica. Oncology 198423 305-313.

12 de Faire U, Friberg L, Lorich U \& Lundman T. A validation of causeof-death certification in 1156 deaths. Acta Medica Scandinavica $1976200223-228$.

13 Lundgren E, Rastad J, Ridefelt P, Juhlin C, Akerstrom G \& Ljunghall S. Long-term effects of parathyroid operation on serum calcium and parathyroid hormone values in sporadic primary hyperparathyroidism. Surgery 1992112 1123-1129.

14 Kjellman M, Sandelin K \& Farnebo LO. Primary hyperparathyroidism. Low surgical morbidity supports liberal attitude to operation. Archives of Surgery 1994129 237-240.

15 Seagroatt $V$ \& Goldace M. Measures of early postoperative mortality: beyond fatality rates. BMJ 1994309 361-364.

16 Nilsson H, Stylianidis G, Haapamäki M, Nilsson E \& Nordin P. Mortality after groin hernia surgery. Annals of Surgery 200745 656-660.

17 Thomusch O, Machens A, Sekulla C, Ukkat J, Lippert H, Gastinger I \& Dralle $\mathrm{H}$. Multivariate analysis of risk factors for postoperative complications in benign goiter surgery: prospective multicenter study in Germany. World Journal of Surgery 200024 1335-1341.

18 Hedbäck G \& Odén A. Increased risk of death from primary hyperparathyroidism - an update. European Journal of Clinical Investigation 199828 271-276.

19 Nilsson IL, Wadsten C, Brandt L, Rastad J \& Ekbom A. Mortality in sporadic primary hyperparathyroidism: nationwide cohort study of multiple parathyroid gland disease. Surgery $2004 \mathbf{1 3 6}$ 981-987.

20 Andersson P, Rydberg E \& Willenheimer R. Primary hyperparathyroidism and heart disease - a review. European Heart Journal 200425 1776-1787.

21 Nilsson IL, Zedenius J, Yin L \& Ekbom A. The association between primary hyperparathyroidism and malignancy: nationwide cohort analysis on cancer incidence after parathyroidectomy. Endocrine-Related Cancer 200714 135-140.

22 Lew JI, Solorzano CC \& Irvin GL. Long-term results of parathyroidectomy for hypercalcemic crisis. Archives of Surgery $2006141696-699$.

23 Harjit K, Zanariah H \& Hisham A. Hypercalcaemic crisis: immediate parathyroidectomy and intraoperative intravenous calcium infusion improves outcome. Asian Journal of Surgery 200730 173-177.

24 Bergenfelz A, Jansson S, Mårtensson H, Reihnér E, Wallin G, Kristoffersson A \& Lausen I. Scandinavian quality register for thyroid and parathyroid surgery: audit of surgery for primary hyperparathyroidism. Langenbeck's Archives of Surgery 2007392 $445-451$.

Received 9 November 2008

Accepted 13 November 2008 